\title{
Incidence and Trends of Leishmaniasis and Its Risk Factors in Humera, Western Tigray
}

\author{
Dawit Gebremichael Tedla ${ }^{D}$, ${ }^{1}$ Fsahatsion Hailemariam Bariagabr, ${ }^{2}$ \\ and Hagos Hadgu Abreha ${ }^{2}$ \\ ${ }^{1}$ Aksum University Shire Campus, College of Agriculture, Veterinary Public Health, Department of Animal Science, Shire, Ethiopia \\ ${ }^{2}$ Aksum University Shire Campus, College of Agriculture, Department of Animal Science, Shire, Ethiopia
}

Correspondence should be addressed to Dawit Gebremichael Tedla; dr.dawit95@yahoo.com

Received 21 April 2018; Revised 17 August 2018; Accepted 5 September 2018; Published 24 September 2018

Academic Editor: José F. Silveira

Copyright (C) 2018 Dawit Gebremichael Tedla et al. This is an open access article distributed under the Creative Commons Attribution License, which permits unrestricted use, distribution, and reproduction in any medium, provided the original work is properly cited.

\begin{abstract}
Introduction. Leishmaniasis is a neglected vector borne disease, which constitutes a major public health concern in several tropical and subtropical countries. An estimated 4500 to 4000 new cases of visceral leishmaniasis (VL) occur per year and over 3.2 million people are at risk of infection in the country. In Humera, VL epidemics are associated with migration of workers from nonendemic highlands into the visceral leishmaniasis endemic extensive farmlands. Therefore, the objective of this study is to estimate the incidence and the risk factors of leishmaniasis in Humera, Western Tigray. Methods. A retrospective study was conducted using the hospital admission database on all patients admitted who have been suspected of having leishmaniasis infection and tested for rK39-based immune chromatographic test (ICT) at Kahsay Abera Hospital in Humera town from January 2012 to December 2017. Potential risk factors for leishmaniasis infection in human were collected from the hospital, which included categorical variables: age, sex, origin of place, clinical forms of leishmaniasis, mortality rates, and the occurrence of infections according to format of hospital. Results. A total of 26511 hospital discharged patients with diagnosis of leishmaniasis were identified, out of which 2232 (8.42\%) human leishmaniasis cases were registered and of them 71 were dead from January 2012 to December 2017. Mortality rates of leishmaniasis were $18(3.3 \%)$ in 2012, 16 (3.1\%) in 2013, $15(2.4 \%)$ in 2014, 8 (3.3\%) in 2015, 9 (4.1\%) in 2016, and 5 (5.4\%) in 2017. Univariate analysis of the infection rate of leishmaniasis was based on the potential risk factors and found higher male infection rates than female $(\mathrm{P}<0.05)$ in all the study years. Origin of place was also significantly associated $(\mathrm{P}<0.05)$ where labor migrants from highland to agricultural fields had higher infection rates than those who permanently lived in and around Humera. Trends in season of occurrence revealed that weeding and harvesting time (July-December) had higher incidence of leishmaniasis than dry time (January-June). Conclusion. Male labor migrants from the highlands older than 15 years of age were at the highest risks of leishmaniasis during weeding and harvest season. Therefore, awareness creation on the risks of sleeping outdoors and the impact of using of bed nets is imperative especially for labor migrants during weeding and harvesting season.
\end{abstract}

\section{Introduction}

Leishmaniasis is a serious and often fatal neglected tropical disease (NTD) which mainly affects the poorest of the poor and is associated with malnutrition, population displacement, poor housing, and a weak immune system $[1,2]$. It can be caused by several species of obligate intracellular protozoan of the genus Leishmania, which constitutes a major public health concern in several tropical and subtropical countries [3-6]. Leishmaniasis has emerged or reemerged in many geographical areas, which increases global health and economic concerns that involved humans, domestic animals, and wild life [6]. Although human-biting sandflies occur in some other genera, the only proven vectors of human disease are the bite of phlebotomine female sand flies of the subspecies of Phlebotomus in the Old World and Lutzomyia in the New World [7-9]. There are three clinical forms of leishmaniasis: visceral (also known as kala-azar), cutaneous, and mucocutaneous. VL is the most severe form of leishmaniasis, almost always fatal if untreated $[10,11]$. 
It is endemic in 98 countries with greater than 350 million people at risk: an estimated 700 000-1.2 million new cases, 600000 to 1 million added new cases annually of cutaneous, 50000 to 90000 new cases of visceral leishmaniasis, and about 20,000 to 40,000 deaths from the disease each year [10-14]. Over $90 \%$ of the annual incidences of VL occur in six countries, namely, Bangladesh, India, Nepal, Sudan, South Sudan, Ethiopia, and Brazil [10, 14-19]. Eastern Africa is the second largest VL focus after the Indian subcontinent, which contributes to the global burden with 30,000-40,000 new cases per year $[10,14]$.

In Ethiopia, VL mainly occurs in the arid and semiarid areas; however, recent reports indicate spreading of the disease to areas where it was previously nonendemic [10]. The increase in leishmaniasis worldwide incidence is mainly due to the increase of several risk factors that are clearly manmade and include environmental modifications, socioeconomic status, expansion of agricultural mega projects, and new reservoir hosts $[1,20,21]$.

An estimated 4,500 to 5000 new cases of VL occur per year and over 3.2 million people are at risk of infection in the country [10, 22-24]; one-third of the country's landmass is highly suitable for VL [21]. Humera town, Western Tigray, and Metema plains constitute the main VL endemic area in the country, contributing over $60 \%$ to the burden [22]. In Western Tigray, the woodland cover is in process of being replaced by extensive commercial agriculture which produces sesame as the main cash crop. The agricultural activities (weeding and harvest) attract around 200,000 seasonal labor migrants annually, mainly from the surrounding Amhara and Tigray highland areas to Humera, Western Tigray lowlands $[25,26]$. VL epidemics are associated with migration and the movement of nonimmune workers from nonendemic highlands into the VL-endemic extensive farmlands [10]. Therefore, the objective of this study is to estimate the incidence and the risk factors of leishmaniasis in Humera, Western Tigray.

\section{Methods and Materials}

2.1. Study Area Description. The study was conducted at Kahsay Abera Hospital in Humera town (Figure 1) from September to December, 2017. It is located in the western zone of the Tigray Region at longitude and latitude $14^{\circ} 18^{\prime} \mathrm{N}$ $36^{\circ} 37^{\prime} \mathrm{E}$, with an elevation of 585 meters above sea level and the Tekeze River runs to the west. By road, it is 984 $\mathrm{km}$ northwest of Addis Ababa, $515 \mathrm{~km}$ west of Mekelle. Humera is the last important Ethiopian city south of the border with Eritrea and Sudan and is considered to be a strategically important gateway to Sudan. The overall climate throughout the year is mild and dry. The annual rainfall ranges between 400 and $600 \mathrm{~mm}$, with most of the rain falling in the rainy season (June up to September). This town has a total population of 21,653 , of whom 11,395 are men and 10,258 are women. The population increases dramatically during the farming season each year, when migrant workers arrive from Amhara region and Northwestern, central and eastern zone of Tigray region. Sesame, sorghum, and Arabic gum are among the most common crops. Labor migrants engaged in removing weeds from sesame seedlings, mostly after establishing themselves in the agricultural fields. But, some labor migrants return to their home at the end of August to take care of their own farm activities at home. Yet, there are some labor migrants who would come to the lowlands in September-October to harvest [27].

2.2. Study Design. A retrospective descriptive study was conducted using the hospital admission database, which includes all patients who were diagnosed with leishmaniasis to estimate the incidence of six-year data from Kahsay Abera Hospital's annual disease report database.

2.3. Data Collection Methods. The study was conducted on all patients admitted who have been suspected of having leishmaniasis infection and tested for rK39-based immune chromatographic test (ICT) at Kahsay Abera Hospital in Humera town from January 2012 to December 2017. Potential risk factors for leishmaniasis infection in human were collected from the hospital, which included categorical variables: age ( $0-4,5-14$, and $\geq 15$ years), sex (male vs. female), origin of place (came from highland to agricultural fields vs. permanently living in and around Humera), clinical forms of leishmaniasis (visceral vs. cutaneous), mortality rates, and the occurrence of infections (harvesting time from July to December vs. dry time from January to June according to format of hospital).

2.4. Data Management and Analysis. Data were coded, checked, and uploaded into Microsoft Excel 2010 spreadsheet computer program and analyzed using STATA version 11.0 for Windows (Stata Corp., College Station, USA). Univariate and binary logistic regression performed utilizing the same program for the first set of questions included sex, age, season, and origin. 95\% confidence intervals were computed and a P value $<0.05$ was considered statistically significant.

2.5. Ethical Approval. Ethical approval was obtained from Aksum University Shire Campus, Research and Ethical Review Committee. Consent was also sought from the hospital administration before being involved.

\section{Results}

3.1. Trends of Incidence of Leishmaniasis. A total of 26511 hospital discharged patients with diagnosis of leishmaniasis were identified, out of which 2232 (8.42\%) human leishmaniasis cases were registered and from these cases, 71 were dead from January 2012 to December 2017. The results showed that leishmaniasis cases decreased across the study years with the highest recorded in 2014. Mortality rates of leishmaniasis were $18(3.3 \%)$ in $2012,16(3.1 \%)$ in $2013,15(2.4 \%)$ in 2014 , $8(3.3 \%)$ in $2015,9(4.1 \%)$ in 2016, and $5(5.4 \%)$ in 2017 (Figure 2). In the hospital leishmaniasis database, victim age was obtained and clustered in three categories: $0-4,5$ to 14, and $\geq 15$ years. Accordingly, the highest leishmaniasis cases were recorded in the age group of $\geq 15$ years in all the six years. Leishmaniasis cases were higher in males than females in all study years (Table 1). 
TABLE 1: Trends of leishmaniasis in relation to age and sex.

\begin{tabular}{|c|c|c|c|c|}
\hline Year & & & No. of cases & Percent \\
\hline \multirow{7}{*}{2012} & \multirow{4}{*}{ Age in years } & $0-4$ & 74 & 13.6 \\
\hline & & 5 to 14 & 85 & 15.6 \\
\hline & & $\geq 15$ & 387 & 70.8 \\
\hline & & Total & 546 & 100 \\
\hline & \multirow{3}{*}{ Sex } & Female & 74 & 13.6 \\
\hline & & Male & 472 & 86.4 \\
\hline & & Total & 546 & 100 \\
\hline \multirow{7}{*}{2013} & \multirow{4}{*}{ Age } & $0-4$ & 58 & 11.4 \\
\hline & & 5 to 14 & 60 & 11.8 \\
\hline & & $\geq 15$ & 392 & 76.9 \\
\hline & & Total & 510 & 100 \\
\hline & \multirow{3}{*}{ Sex } & Female & 63 & 12.4 \\
\hline & & Male & 447 & 87.6 \\
\hline & & Total & 510 & 100 \\
\hline \multirow{7}{*}{2014} & \multirow{4}{*}{ Age } & $0-4$ & 29 & 4.7 \\
\hline & & 5 to 14 & 104 & 16.9 \\
\hline & & $\geq 15$ & 484 & 78.4 \\
\hline & & Total & 617 & 100 \\
\hline & \multirow{3}{*}{ Sex } & Female & 39 & 6.3 \\
\hline & & Male & 578 & 93.7 \\
\hline & & Total & 617 & 100 \\
\hline \multirow{7}{*}{2015} & \multirow{4}{*}{ Age } & $0-4$ & 22 & 9.0 \\
\hline & & 5 to 14 & 24 & 9.8 \\
\hline & & $\geq 15$ & 199 & 81.2 \\
\hline & & Total & 245 & 100 \\
\hline & \multirow{3}{*}{ Sex } & Female & 27 & 11.0 \\
\hline & & Male & 218 & 89.0 \\
\hline & & Total & 245 & 100 \\
\hline \multirow{7}{*}{2016} & \multirow{4}{*}{ Age } & $0-4$ & 22 & 9.9 \\
\hline & & 5 to 14 & 25 & 11.3 \\
\hline & & $\geq 15$ & 175 & 78.8 \\
\hline & & Total & 222 & 100 \\
\hline & \multirow{3}{*}{ Sex } & Female & 38 & 17.1 \\
\hline & & Male & 184 & 82.9 \\
\hline & & Total & 222 & 100 \\
\hline \multirow{7}{*}{2017} & \multirow{4}{*}{ Age } & $0-4$ & 2 & 2.2 \\
\hline & & 5 to 14 & 6 & 6.5 \\
\hline & & $\geq 15$ & 84 & 91.3 \\
\hline & & Total & 92 & 100 \\
\hline & \multirow{3}{*}{ Sex } & Female & 3 & 3.3 \\
\hline & & Male & 89 & 96.7 \\
\hline & & Total & 92 & 100 \\
\hline
\end{tabular}

Highest occurrences of the cases were those admitted during harvesting time from July to December compared to dry time from January to June in all the study years. The highest incidence of leishmaniasis was found in workers who came from highland to agricultural fields compared to those who permanently lived in and around Humera in all six years (Table 2). Regarding types of leishmaniasis, 544 (99.6\%) and 2 $(0.4 \%)$ in 2012, $508(99.6 \%)$ and $2(0.4 \%)$ in 2013,615 (99.7\%) and $2(0.3 \%)$ in 2014, $245(100 \%)$ in 2015, $206(92.8 \%)$ and 16 (7.2) in 2016, and $92(100 \%)$ in 2017 were visceral and cutaneous leishmaniasis, respectively.

3.2. Incidence of Leishmaniasis in relation to Risk Factors. The likelihood of infection was also significantly higher in the group greater than 15 years in all the study years. Univariate analysis of the infection rate of leishmaniasis was based on the 
TABLE 2: Trends of leishmaniasis in relation to season and origin.

\begin{tabular}{|c|c|c|c|c|}
\hline Year & & and origin & No. of cases & Percent \\
\hline \multirow{6}{*}{2012} & \multirow{3}{*}{ Season } & Dry time & 241 & 44.14 \\
\hline & & Weeding and harvesting time & 305 & 55.86 \\
\hline & & Total & 546 & 100 \\
\hline & \multirow{3}{*}{ Origin } & Lowland & 248 & 45.4 \\
\hline & & Highland & 298 & 54.6 \\
\hline & & Total & 546 & 100 \\
\hline \multirow{6}{*}{2013} & \multirow{3}{*}{ Season } & Dry time & 207 & 40.59 \\
\hline & & Weeding and harvesting time & 303 & 59.41 \\
\hline & & Total & 510 & 100 \\
\hline & \multirow{3}{*}{ Origin } & Lowland & 232 & 45.5 \\
\hline & & Highland & 278 & 54.5 \\
\hline & & Total & 510 & 100 \\
\hline \multirow{6}{*}{2014} & \multirow{3}{*}{ Season } & Dry time & 282 & 45.71 \\
\hline & & Weeding and harvesting time & 335 & 54.29 \\
\hline & & Total & 617 & 100 \\
\hline & \multirow{3}{*}{ Origin } & Lowland & 201 & 32.6 \\
\hline & & Highland & 416 & 67.4 \\
\hline & & Total & 617 & 100 \\
\hline \multirow{6}{*}{2015} & \multirow{3}{*}{ Season } & Dry time & 97 & 39.6 \\
\hline & & Weeding and harvesting time & 148 & 60.4 \\
\hline & & Total & 245 & 100 \\
\hline & \multirow{3}{*}{ Origin } & Lowland & 96 & 39.2 \\
\hline & & Highland & 149 & 60.8 \\
\hline & & Total & 245 & 100 \\
\hline \multirow{6}{*}{2016} & \multirow{3}{*}{ Season } & Dry time & 89 & 40.1 \\
\hline & & Weeding and harvesting time & 133 & 59.9 \\
\hline & & Total & 222 & 100 \\
\hline & \multirow{3}{*}{ Origin } & Lowland & 99 & 44.6 \\
\hline & & Highland & 123 & 55.4 \\
\hline & & Total & 222 & 100 \\
\hline \multirow{6}{*}{2017} & \multirow{3}{*}{ Season } & Dry time & 30 & 32.61 \\
\hline & & Weeding and harvesting time & 62 & 67.39 \\
\hline & & Total & 92 & 100 \\
\hline & \multirow{3}{*}{ Origin } & Lowland & 35 & 38 \\
\hline & & Highland & 57 & 62 \\
\hline & & Total & 92 & 100 \\
\hline
\end{tabular}

potential risk factors and found higher male infection rates than female $(\mathrm{P}<0.05)$ in all the study years (Table 3$)$. Origin of place was also significantly associated $(\mathrm{P}<0.05)$ where labor migrants from highland to agricultural fields had higher infection rates than those who permanently lived in and around Humera. Trends in season of occurrence revealed that weeding and harvesting time (July-December) had higher incidence of leishmaniasis than dry time (January-June) (Table 4).

\section{Discussions}

The study provided a 6-year review of the epidemiological trends and all hospital discharged patients only to diagnose leishmaniasis in Humera. A total of 2232 human leishmaniasis cases were registered and the incidence of leishmaniasis was decreased across the study years. The reason could be mainly due to the fact that the government of Ethiopia, particularly Tigray regional state, has developed its own control strategies so as to limit the rapid spread of the disease. A national leishmaniasis task force was established in 2007 with the aim of eliminating VL and hospitals and health centers in endemic regions equipped to treat VL include Kahsay Abera Humera Hospital, Aksum Hospital, and Mekelle Hospital in Tigray regional state [28]. But, the incidence peaked in 2014 exceptionally. Sometimes, a sudden outbreak of leishmaniasis was common in this area. It may be due to the fact that the large-scale labor migrants visited this endemic area from highland. 
TABLE 3: Incidence of leishmaniasis in relation to age and sex with all diagnosed patients for leishmaniasis.

\begin{tabular}{|c|c|c|c|c|c|c|c|}
\hline Year & & tors & Admitted & No. of cases & Percent & OR $(95 \% \mathrm{CI})$ & P value \\
\hline \multirow{7}{*}{2012} & \multirow{4}{*}{ Age } & $0-4$ & 910 & 74 & 8.13 & \multirow{4}{*}{$1.63(1.11,2.72)$} & \multirow{4}{*}{$<0.000$} \\
\hline & & 5 to 14 & 908 & 85 & 9.36 & & \\
\hline & & $\geq 15$ & 1240 & 387 & 31.20 & & \\
\hline & & Total & 3058 & 546 & 17.85 & & \\
\hline & \multirow{3}{*}{ Sex } & Female & 1418 & 74 & 5.22 & \multirow{3}{*}{$1.7(1.42-2.35)$} & \multirow{3}{*}{$<0.000$} \\
\hline & & Male & 1640 & 472 & 28.78 & & \\
\hline & & Total & 3058 & 546 & 17.85 & & \\
\hline \multirow{7}{*}{2013} & \multirow{4}{*}{ Age } & $0-4$ & 1016 & 58 & 5.71 & \multirow{3}{*}{$1.8(1.45,2.80)$} & \multirow{4}{*}{$<0.000$} \\
\hline & & 5 to 14 & 1009 & 60 & 5.95 & & \\
\hline & & $\geq 15$ & 1577 & 392 & 24.86 & & \\
\hline & & Total & 3602 & 510 & 14.16 & & \\
\hline & \multirow{3}{*}{ Sex } & Female & 1685 & 63 & 3.74 & \multirow{3}{*}{$1.9(1.1,3.6)$} & \multirow{3}{*}{$<0.000$} \\
\hline & & Male & 1917 & 447 & 23.32 & & \\
\hline & & Total & 3602 & 510 & 14.16 & & \\
\hline \multirow{7}{*}{2014} & \multirow{4}{*}{ Age } & $0-4$ & 1103 & 29 & 2.63 & \multirow{3}{*}{$1.93(1.3,2.96)$} & \multirow{4}{*}{$<0.000$} \\
\hline & & 5 to 14 & 1352 & 104 & 7.69 & & \\
\hline & & $\geq 15$ & 1821 & 484 & 26.58 & & \\
\hline & & Total & 4276 & 617 & 14.42 & & \\
\hline & \multirow{3}{*}{ Sex } & Female & 1230 & 39 & 3.17 & \multirow{3}{*}{$1.81(1.00,3.45)$} & \multirow{3}{*}{$<0.000$} \\
\hline & & Male & 3046 & 578 & 17.98 & & \\
\hline & & Total & 4276 & 617 & 14.42 & & \\
\hline \multirow{7}{*}{2015} & \multirow{4}{*}{ Age } & $0-4$ & 1600 & 22 & 1.38 & \multirow{4}{*}{$1.67(1.01,2.02)$} & \\
\hline & & 5 to 14 & 1680 & 24 & 1.43 & & $<0000$ \\
\hline & & $\geq 15$ & 1707 & 199 & 11.66 & & $<0.000$ \\
\hline & & Total & 4987 & 245 & 4.91 & & \\
\hline & & Female & 2665 & 27 & 1.01 & & \\
\hline & Sex & Male & 2322 & 218 & 9.39 & $1.89(1.2,2.80)$ & $<0.000$ \\
\hline & & Total & 4987 & 245 & 4.91 & & \\
\hline & & $0-4$ & 1494 & 22 & 1.47 & & \\
\hline & Age & 5 to 14 & 1582 & 25 & 1.57 & $191(1.08,2.72)$ & $<0.000$ \\
\hline & & $\geq 15$ & 1706 & 175 & 10.26 & & \\
\hline 2016 & & Total & 4782 & 222 & 4.64 & & \\
\hline & & Female & 2393 & 38 & 1.60 & & \\
\hline & Sex & Male & 2389 & 184 & 7.70 & $1.5(1.0 .2 .52)$ & $<0.000$ \\
\hline & & Total & 4782 & 222 & 4.64 & & \\
\hline & & $0-4$ & 1706 & 2 & 0.11 & & \\
\hline & Age & 5 to 14 & 1838 & 6 & 0.33 & $16(11,150)$ & $<0.03$ \\
\hline & & $\geq 15$ & 2262 & 84 & 3.71 & & \\
\hline 2017 & & Total & 5806 & 92 & 1.60 & & \\
\hline & & Female & 2710 & 3 & 0.11 & & \\
\hline & Sex & Male & 3096 & 89 & 2.87 & $1.4(0.98,1.27)$ & $<0.04$ \\
\hline & & Total & 5806 & 92 & 1.60 & & \\
\hline
\end{tabular}

According to available data in the Kahsay Abera Hospital, the disease was distributed in the various age groups, but occurred most frequently in the age group of greater than 15 years old $(\mathrm{P}<0.000)$. It might be due to the fact that matured migrant agricultural workers are highly exposed to sandfly. According to Leta et al. [10], all age groups are susceptible but most cases occur in groups that have regular contact with sandfly habitats. A similar result was reported where the number of patients admitted for visceral leishmaniasis was higher than that of the age group of greater than 16 years old $[29,30]$.

Univariate analysis revealed that being male was a risk for leishmaniasis exposure in all the study years. This gender difference might be due to difference in outdoor activity between males and females. This might be associated with activities of males in that they engage in outdoor activities 
TABLE 4: Incidence of leishmaniasis in relation to season and origin with all diagnosed patients for leishmaniasis.

\begin{tabular}{|c|c|c|c|c|c|c|c|}
\hline Year & & Risk factors & Admitted & No. of cases & Percent & OR $(95 \% \mathrm{CI})$ & P value \\
\hline \multirow{6}{*}{2012} & \multirow{3}{*}{ Season } & Dry time & 1650 & 241 & 14.60 & \multirow{3}{*}{$1.54(1.4,2.52)$} & \multirow{3}{*}{$<0.01$} \\
\hline & & Weeding and harvesting time & 1408 & 305 & 21.66 & & \\
\hline & & Total & 3058 & 546 & 17.85 & & \\
\hline & \multirow{3}{*}{ Origin } & Lowland & 2001 & 248 & 13.39 & \multirow{3}{*}{$1.8(0.94,2.92)$} & \multirow{3}{*}{$<0.000$} \\
\hline & & Highland & 1057 & 298 & 28.19 & & \\
\hline & & Total & 3058 & 546 & 17.85 & & \\
\hline \multirow{6}{*}{2013} & \multirow{3}{*}{ Season } & Dry time & 1837 & 207 & 11.27 & \multirow{3}{*}{$1.4(0.85,1.99)$} & \multirow{3}{*}{$<0.000$} \\
\hline & & Weeding and harvesting time & 1765 & 303 & 17.17 & & \\
\hline & & Total & 3602 & 510 & 14.16 & & \\
\hline & \multirow{3}{*}{ Origin } & Lowland & 2423 & 232 & 9.57 & \multirow{3}{*}{$1.9(0.84,2.92)$} & \multirow{3}{*}{$<0.000$} \\
\hline & & Highland & 1179 & 278 & 23.58 & & \\
\hline & & Total & 3602 & 510 & 14.16 & & \\
\hline \multirow{6}{*}{2014} & \multirow{3}{*}{ Season } & Dry time & 2450 & 282 & 11.51 & \multirow{3}{*}{$1.5(1.22,1.97)$} & \multirow{3}{*}{$<0.003$} \\
\hline & & Weeding and harvesting time & 1826 & 335 & 18.35 & & \\
\hline & & Total & 4276 & 617 & 14.43 & & \\
\hline & \multirow{3}{*}{ Origin } & Lowland & 2651 & 201 & 7.58 & \multirow{3}{*}{$1.9(1.40,3.01)$} & \multirow{3}{*}{$<0.000$} \\
\hline & & Highland & 1625 & 416 & 25.60 & & \\
\hline & & Total & 4276 & 617 & 14.43 & & \\
\hline \multirow{6}{*}{2015} & \multirow{3}{*}{ Season } & Dry time & 2870 & 97 & 3.38 & \multirow{3}{*}{$1.45(1.11,1.83)$} & \multirow{3}{*}{$<0.02$} \\
\hline & & Weeding and harvesting time & 2117 & 148 & 6.99 & & \\
\hline & & Total & 4987 & 245 & 4.91 & & \\
\hline & \multirow{3}{*}{ Origin } & Lowland & 2985 & 96 & 3.22 & \multirow{3}{*}{$1.6(1.7,2.23)$} & \\
\hline & & Highland & 2002 & 149 & 7.44 & & $<0.000$ \\
\hline & & Total & 4987 & 245 & 4.91 & & \\
\hline & & Dry time & 2575 & 89 & 3.46 & & \\
\hline & Season & Weeding and harvesting time & 2207 & 133 & 6.03 & $1.6(1.6,2.02)$ & $<0.001$ \\
\hline 2016 & & Total & 4782 & 222 & 4.64 & & \\
\hline 2016 & & Lowland & 2866 & 99 & 3.45 & & \\
\hline & Origin & Highland & 1916 & 123 & 6.42 & $1.8(1.6,2.18)$ & $<0.000$ \\
\hline & & Total & 4782 & 222 & 4.64 & & \\
\hline & & Dry time & 2930 & 30 & 1.02 & & \\
\hline & Season & Weeding and harvesting time & 2876 & 62 & 2.16 & $1.3(0.75,1.6)$ & $<0.04$ \\
\hline 2017 & & Total & 5806 & 92 & 1.85 & & \\
\hline 2017 & & Lowland & 3501 & 35 & 1.00 & & \\
\hline & Origin & Highland & 2305 & 57 & 2.47 & $1.5(1.1,1.9)$ & $<0.001$ \\
\hline & & Total & 5806 & 92 & 1.85 & & \\
\hline
\end{tabular}

such as weeding and harvesting sesame which will make them more accessible to the sandfly bite while females are more likely to remain indoors due to sociocultural factors. Similarly, sleeping under an acacia tree during the day and habitually sleeping outside at night are associated with significantly increased risk [31]. The majority of VL cases throughout the country occur in males, a pattern caused by increased exposure to the sandfly vector during agricultural work [28]. A study conducted by Oryan and Akbari [6] indicated a significant association between sex and leishmaniasis; more likely men were exposed to sandflies in fields and other open areas more than women.

Humera and its surrounding areas have significant economic input for the country because cash crops such as sesame, cotton, and sorghum are grown at a commercial scale. Thousands of male migrant workers arrive every year during the agricultural season (June-November). More than $80 \%$ of patients with VL were male migrant workers infected with $L$. donovani who sleep in the farm [29]. A similar finding was also reported in other studies [30]. This gender difference might be due to difference in outdoor activity between males and females. As indicated in another study, males are more involved in outdoor activities than females in the study area and this may have made them more susceptible to the bite of sand flies.

People who come from highlands of Tigray and Amhara regions for weeding and harvesting sesame are at higher risk of leishmaniasis infection as compared to those living 


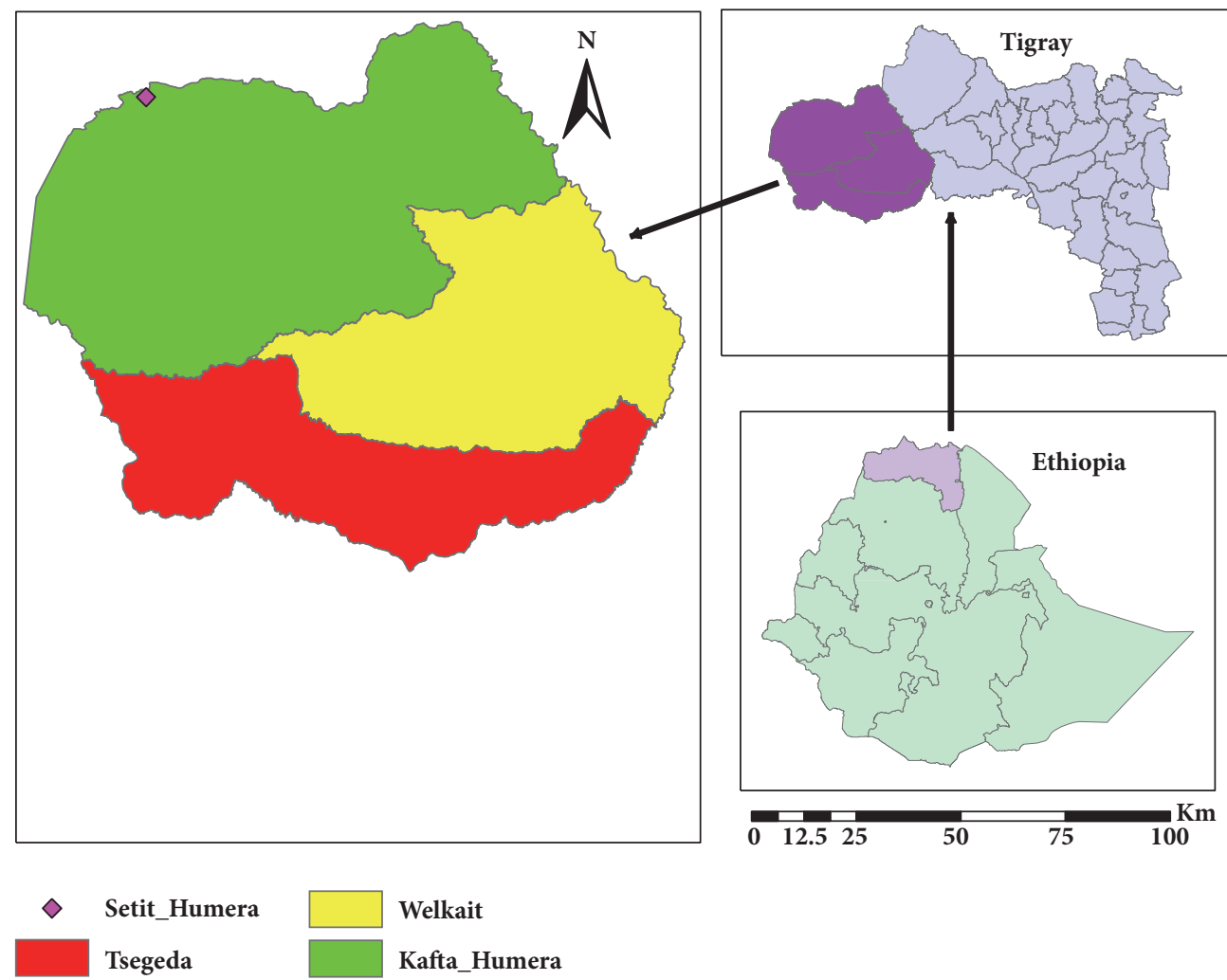

FIGURE 1: Western Tigray map showing the study area.

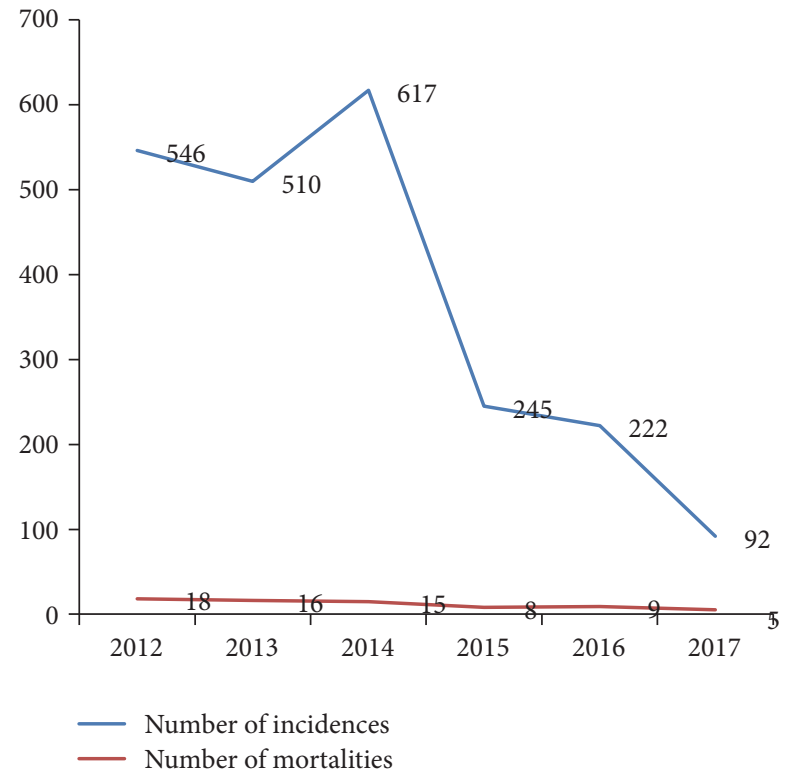

Figure 2: Trends of leishmaniasis in Kahsay Abera Hospital from 2012 to 2017.

permanently in and around Humera. People who came from highlands are highly exposed to sandfly due to sleeping in the farm and camp outside the house. The reason might be due to the fact that epidemics of VL are often associated with migration and the introduction of nonimmune people into areas with existing transmission cycles and most of the migrants are living outside the home. Lemma et al. [26] reported similar findings that people sleeping in the farm were more likely to have sero-reaction than those sleeping in the house. Following agricultural development in the area, a large number of labor migrants from the highlands were moved to the endemic areas for sesame harvesting. This led to spread of visceral leishmaniasis, which resulted in high morbidity and mortality in Humera [32]. There was a marked difference of prevalence in the farming (45.6\%) and nonfarming (8.3\%) communities which showed that overall skin test positivity increased with the duration of stay in the area [21].

There was statistically significant difference between infection rate and seasons in all the study years. It may be due to the fact that labor migrants are most probably exposed to leishmaniasis during June-August weeding season and staying during September-October harvest season. Epidemic outbreaks were common during weeding and harvesting times. In weeding and harvesting season, workers sleep outside the house and they could not use bed nets. Gadisa et al. [21] suggested that $P$. orientalis shifts from their breeding habitats to possible shelters like grass huts of labor migrants in the camp which might have increased the chance of $P$. orientalis bites or $L$. donovani infection during the weeding season in Humera. 


\section{Conclusion}

Male labor migrants older than 15 years of age from highlands are the most probably exposed to leishmaniasis during June-August in the weeding season and during September-October in the harvesting season. This might be due to sleeping in the farm and camp outside the house leading to being more accessible to the sandfly bite. Therefore, awareness creation on the risks of sleeping outdoors and the impact of using of bed nets is imperative especially for male labor migrants from the highlands during weeding and harvesting season.

\section{Abbreviations}

CL: Cutaneous leishmaniasis

VL: Visceral leishmaniasis.

\section{Data Availability}

All data generated or analyzed during this study are included in this published article. The datasets used and analyzed during the current study are available from the corresponding author on reasonable request.

\section{Conflicts of Interest}

The authors declare that they have no conflicts of interest.

\section{Authors' Contributions}

Dawit Gebremichael Tedla carried out designing the research and preparing the proposal, data gathering, analyzing the data, and preparing the manuscript. Fsahatsion Hailemariam Bariagabr and Hagos Hadgu Abreha carried out reviewing, editing, and organizing the papers. All authors read and approved the final manuscript.

\section{Acknowledgments}

We are grateful to Kahsay Abera Hospital staffs for their support. We also thank Aksum University for facilitating and partially funding this study.

\section{References}

[1] Z. Assimina, K. Charilaos, and B. Fotoula, "Leishmaniasis: an overlooked public health concern," Health Science Journal, vol. 2, no. 4, pp. 196-205, 2008.

[2] CFSPH, Leishmaniasis (cutaneous and visceral), Center for Food Security and Public Health, Iowa State of University, College of Veterinary Medicine, Iowa, Iowa, USA, 2009.

[3] F. Dantas-Torres, L. Solano-Gallego, G. Baneth, V. M. Ribeiro, M. de Paiva-Cavalcanti, and D. Otranto, "Canine leishmaniosis in the Old and New Worlds: unveiled similarities and differences," Trends in Parasitology, vol. 28, no. 12, pp. 531-538, 2012.

[4] B. S. Lima, F. Dantas-Torres, M. R. De Carvalho et al., "Small mammals as hosts of Leishmania spp.In a highly endemic area for zoonotic leishmaniasis in north-eastern Brazil," Transactions of the Royal Society of Tropical Medicine and Hygiene, vol. 107, no. 9, Article ID trt062, pp. 592-597, 2013.

[5] T. Hailu, M. Yimer, W. Mulu, and B. Abera, "Challenges in visceral leishmaniasis control and elimination in the developing countries: A review," Journal of Vector Borne Diseases, vol. 53, no. 3, pp. 193-198, 2016.

[6] A. Oryan and M. Akbari, "Worldwide risk factors in leishmaniasis," Asian Pacific Journal of Tropical Medicine, vol. 9, no. 10, pp. 925-932, 2016.

[7] F. Dantas-Torres, "The role of dogs as reservoirs of Leishmania parasites, with emphasis on Leishmania (Leishmania) infantum and Leishmania (Viannia) braziliensis," Veterinary Parasitology, vol. 149, no. 3-4, pp. 139-146, 2007.

[8] G. Dawit, Z. Girma, and K. Simenew, "A review on biology, epidemiology and public health significance of leishmaniasis," Journal of Bacteriology \& Parasitology, vol. 4, article 166, 2013.

[9] D. Savoia, "Recent updates and perspectives on leishmaniasis," The Journal of Infection in Developing Countries, vol. 9, no. 06, p. 588, 2015.

[10] S. Leta, T. H. Dao, F. Mesele, G. Alemayehu, and E. Ghedin, "Visceral Leishmaniasis in Ethiopia: An Evolving Disease," PLOS Neglected Tropical Diseases, vol. 8, no. 9, p. e3131, 2014.

[11] R. C. Spear, "Review of "Mathematical Models for Neglected Tropical Diseases: Essential Tools for Control and Elimination, Part B" Edited by Maria-Gloria Basáñez and Roy M. Anderson," Parasites \& Vectors, vol. 10, no. 1, p. 38, 2017.

[12] WHO, Leishmaniasis. Fact sheet, World Health Organization, Geneva, Switzerland, 2015.

[13] P. D. Ready, "Leishmaniasis emergence and climate change," Revue Scientifique et Technique (International Office of Epizootics), vol. 27, no. 2, pp. 399-412, 2008.

[14] O. A, "Risk Factors Associated With Leishmaniasis," Tropical Medicine \& Surgery, vol. 02, no. 03, 2014.

[15] P. Desjeux, "Leishmaniasis: current situation and new perspectives," Comparative Immunology, Microbiology \& Infectious Diseases, vol. 27, no. 5, pp. 305-318, 2004.

[16] H. W. Murray, J. D. Berman, C. R. Davies, and N. G. Saravia, "Advances in leishmaniasis," The Lancet, vol. 366, pp. 1561-1577, 2005.

[17] F. Dantas-Torres and S. P. Brandão-Filho, "Visceral leishmaniasis in Brazil: Revisiting paradigms of epidemiology and control," Revista do Instituto de Medicina Tropical de São Paulo, vol. 48, no. 3, pp. 151-156, 2006.

[18] W. Lemma, H. Tekie, M. Balkew, T. Gebre-Michael, A. Warburg, and A. Hailu, "Population dynamics and habitat preferences of Phlebotomus orientalis in extra-domestic habitats of Kafta Humera lowlands - Kala azar endemic areas in Northwest Ethiopia," Parasites \& Vectors, vol. 7, no. 1, article no. 359, 2014.

[19] WHO, Leishmaniasis. Fact sheet No. 375, World Health Organization, Geneva, Switzerland, 2017, http://www.who.int/ mediacentre/factsheets/fs375/en/.

[20] A. Alcais, L. Abel, C. David, M. E. Torrez, P. Flandre, and J. P. Dedet, "Risk factors for onset of cutaneous and mucocutaneous leishmaniasis in Bolivia," The American Journal of Tropical Medicine and Hygiene, vol. 57, no. 1, pp. 79-84, 1997.

[21] E. Gadisa, T. Tsegaw, A. Abera et al., "Eco-epidemiology of visceral leishmaniasis in Ethiopia," Parasites \& Vectors, vol. 8, no. $1,2015$.

[22] A. Kassahun, J. Sadlova, V. Dvorak et al., "Detection of leishmania donovani and L. tropica in ethiopian wild rodents," Acta Tropica, vol. 145, pp. 39-44, 2015. 
[23] J. Alvar, I. D. Vélez, C. Bern et al., "Leishmaniasis worldwide and global estimates of its incidence," PLoS ONE, vol. 7, no. 5, Article ID e35671, 2012.

[24] A. Seid, E. Gadisa, T. Tsegaw et al., "Risk map for cutaneous leishmaniasis in Ethiopia based on environmental factors as revealed by geographical information systems and statistics," Geospatial Health, vol. 8, no. 2, pp. 377-387, 2014.

[25] H. K. Abbas, R. M. Zablotowicz, and H. A. Bruns, "Modeling the colonization of maize by toxigenic and non-toxigenic Aspergillus flavus strains: implications for biological control," World Mycotoxin Journal, vol. 1, no. 3, pp. 333-340, 2008.

[26] W. Lemma, H. Tekie, S. Yared et al., "Sero-prevalence of Leishmania donovani infection in labour migrants and entomological risk factors in extra-domestic habitats of Kafta-Humera lowlands - kala-azar endemic areas in the northwest Ethiopia," BMC Infectious Diseases, vol. 15, no. 1, 2015.

[27] CSA, National Statistics-Population by Town And Sex, Central Statistical Agency of Ethiopia, 2012.

[28] Malaria. Consortium, Leishmaniasis control in eastern Africa: Past and present efforts and future needs. Situation and gap analysis, 28 Malaria Consortium. Leishmaniasis control in eastern Africa, Past and present efforts and future needs. Situation and gap analysis, 2010.

[29] S. Yared, K. Deribe, A. Gebreselassie et al., "Risk factors of visceral leishmaniasis: A case control study in north-western Ethiopia," Parasites \& Vectors, vol. 7, no. 1, article no. 470, 2014.

[30] S. Y, "Trend Analysis of Visceral Leishmaniasis in Metema Hospital Northwest, Ethiopia," Journal of Epidemiology and Public Health Reviews, vol. 1, no. 5, 2016.

[31] M. Herrero, C. Cañavate, I. D. Vélez et al., "Risk Factors for Visceral Leishmaniasis in a New Epidemic Site in Amhara Region, Ethiopia," The American Journal of Tropical Medicine and Hygiene, vol. 81, no. 1, pp. 34-39, 2009.

[32] A. Desta, S. Shiferaw, A. Kassa, T. Shimelis, and S. Dires, Module on Leishmaniasis for The Ethiopian Health Center Team, Debub University, Ethiopia, 2005. 


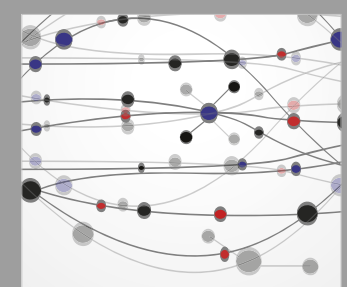

The Scientific World Journal
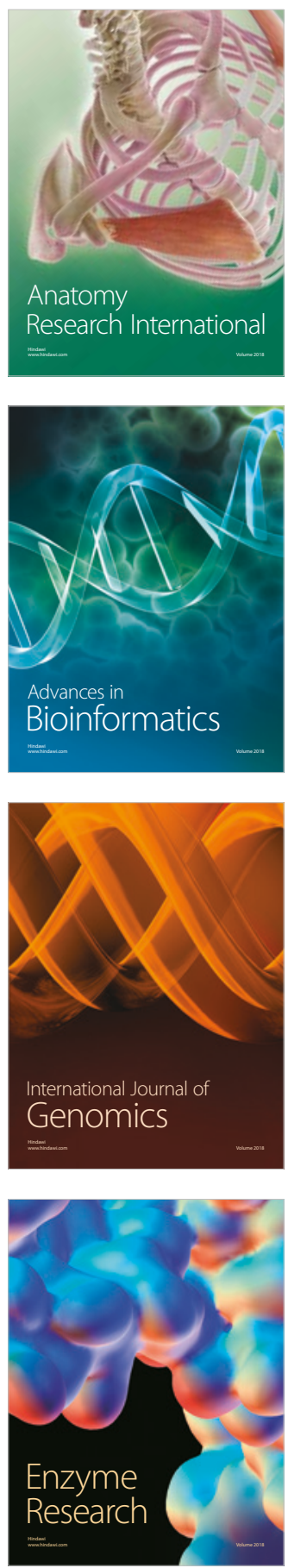
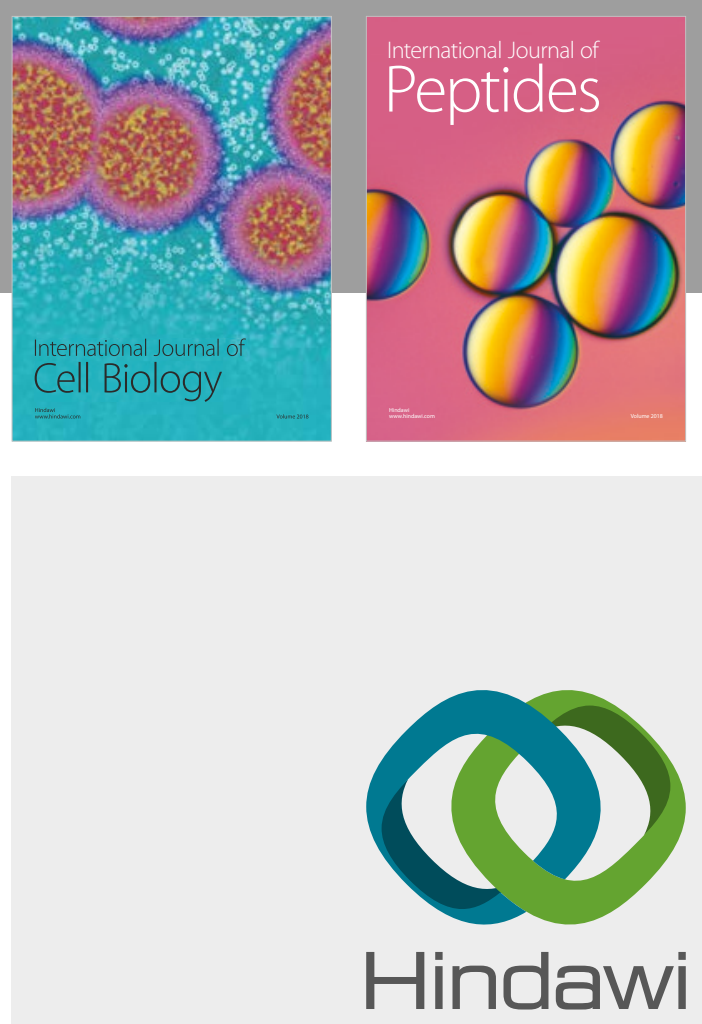

Submit your manuscripts at

www.hindawi.com
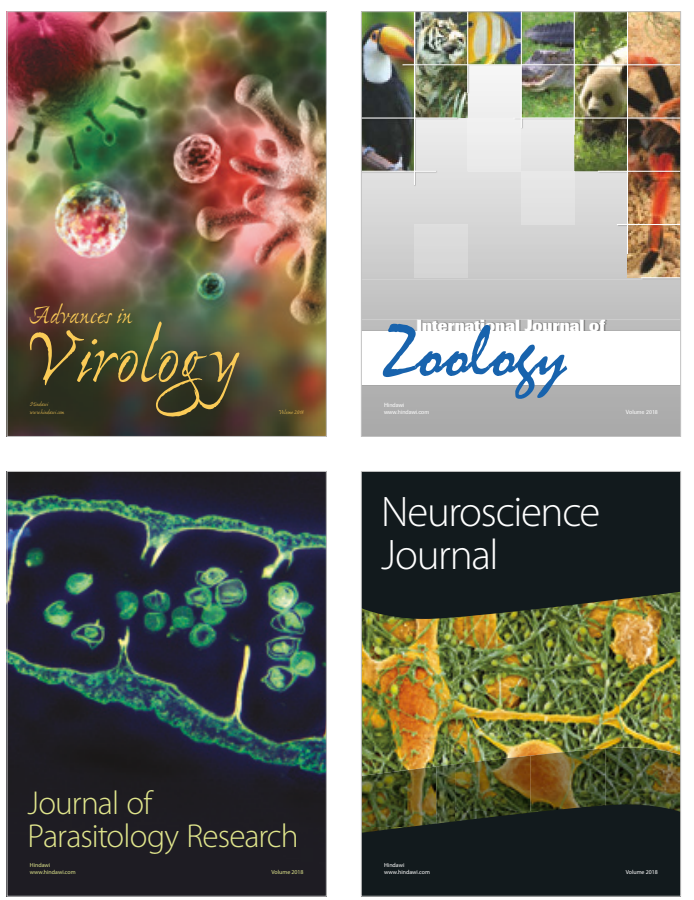
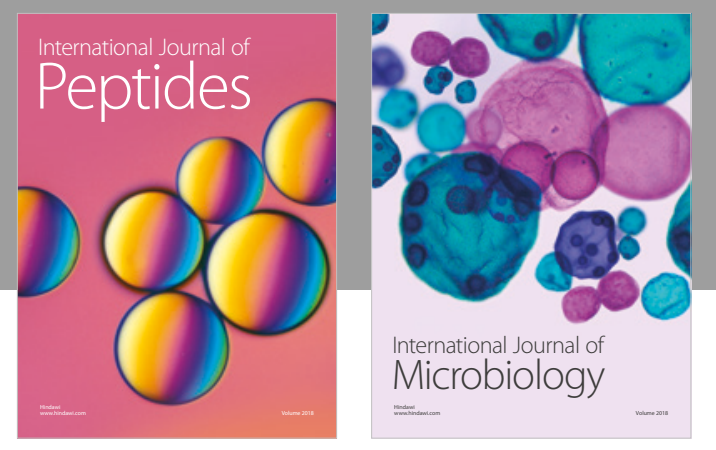

nternational Journal of Microbiology
Journal of
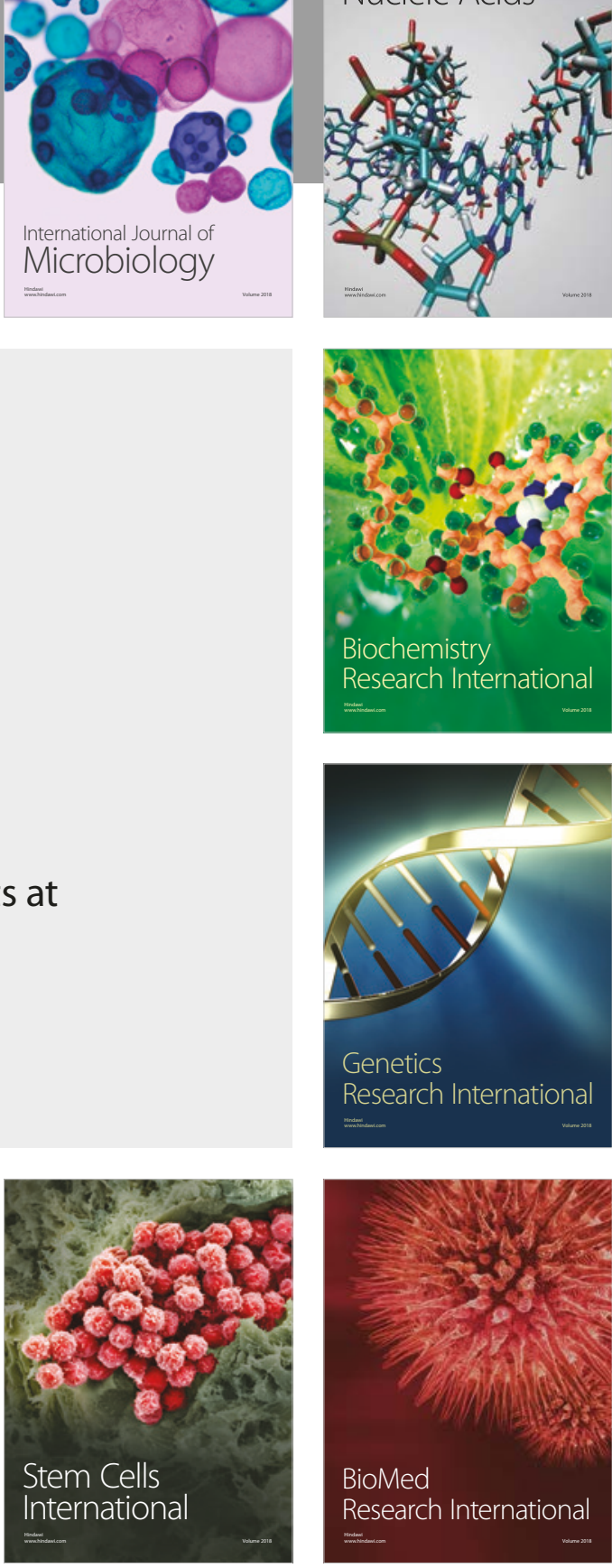
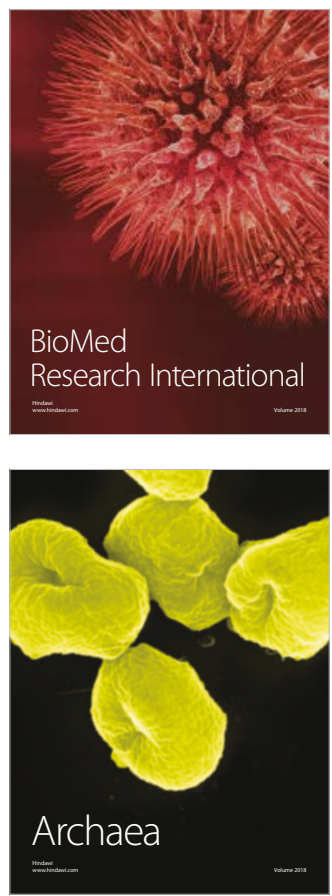